\title{
THE RELATIONSHIP BETWEEN PYRETHRINS AND THE YELLOW PIGMENTATION IN PYRETHRUM FLOWERS
}

\author{
Wenwa A. Odinga and Charles A. Angedu \\ Department of Chemistry, University of Nairobi, P.O. Box 30197, Nairobi, Kenya
}

\begin{abstract}
Various clones and varieties of Chrysanthemum cinerariaefolium flowers originating from various localities were used in this study to establish the link between pyrethrins and the yellow pigments in pyrethrum. Pyrethrins content was determined using spectrophotometric, AOAC and HPLC analytical techniques. Absorbances of I \% (w/v) n-hexane extracts at various wavelengths in the UV and visible regions were read using a double beam spectrophotometer. This paper presents correlations between total Pyrethrins, individual ester distributions, Pyrethrins I and Pyrethrins11 ratios and specific colour absorbances $\left(A^{1 \%} 1 \mathrm{~cm}\right)$ in three different regions $260-300 \mathrm{~nm}\left({ }^{1} \mathrm{~A}^{1 \%} \mathrm{~cm}\right), 300-400 \mathrm{~nm}\left({ }^{2} \mathrm{~A} 1^{\%} \mathrm{~cm}\right)$ and $400-470 \mathrm{~nm}\left({ }^{3} \mathrm{~A}^{1 \%} \mathrm{~cm}\right)$. The results depict negative colour absorbances in all the three regions. The pigments absorbing at 266-300 nm show a better correlation with the pyrethrins than pigments absorbing at 400$470 \mathrm{~nm}$. The pigments at the former region are flavonoids and the latter carotenoids from spectrophotometric scans and TLC screening.
\end{abstract}

\section{INTRODUCTION}

Pyrethrum belongs to the genus Chrysanthemum in the family Compositae. The flowers of the species cinerariefolium have long been exploited commercially for their insecticidal properties. These properties were probably discovered accidentally in 1840 , by a German woman in Dalmatia, who received a bouquet of flowers on her birthday. After a night long partying, she threw the flowers into a corner. In the morning the flowers were surrounded by dead insects. The death of the insects were associated with the insecticidal properties of the insects(Casida,1973). Since then the flower has undergone extensive research establishing its complete, effective and safe commercial exploitation as a source of the natural insecticides collectively known as pyrethrins(Casida; Quistad, 1995)These lie in the central part of the flower head, typically an inflorescence that is yellow. It has been shown that the pyrethrins are more concentrated in the achenes located in the flower head. (Chandler, 1951). To date Kenya is still the largest producer of pyrethrum, well over $70 \%$, in the World. The processed product is mainly exported and earns Kenya a sizeable foreign exchange income It is also in most cases, the main source of income to the farmers that grow it.
Therefore research into a better understanding of the chemical components and characteristics of pyrethrum flowers with a view to devising means and ways of improving the quality of the same, is desirable.

The commercial survival of pyrethrum industry is attributed to the natural pyrethrins low mammalian toxicity, environmental safety and its rapid knock down effect on a wide range of flying insects. The competition from the synthetic pyrethroids and biotechnological substitutes is inferior owing to the above and other advantages of the natural pyrethrins.

Pyrethrins have been isolated and characterised into six closely related esters (fig 1). These esters are formed from a combination of two acids, chrysanthemic and pyrethric acids, with three alcohols, jasmololone 3, cinerolone 4 and pyrethrolone 5. The chrysanthemates are called jasmolin 1 , cinerin 1 and pyrethrin 1 and combined make up the pyrethrins I while the esters of pyrethric acid jasmolin 2 , cinerin 2 and pyrethrin 2 are referred to as pyrethrins 11 . 


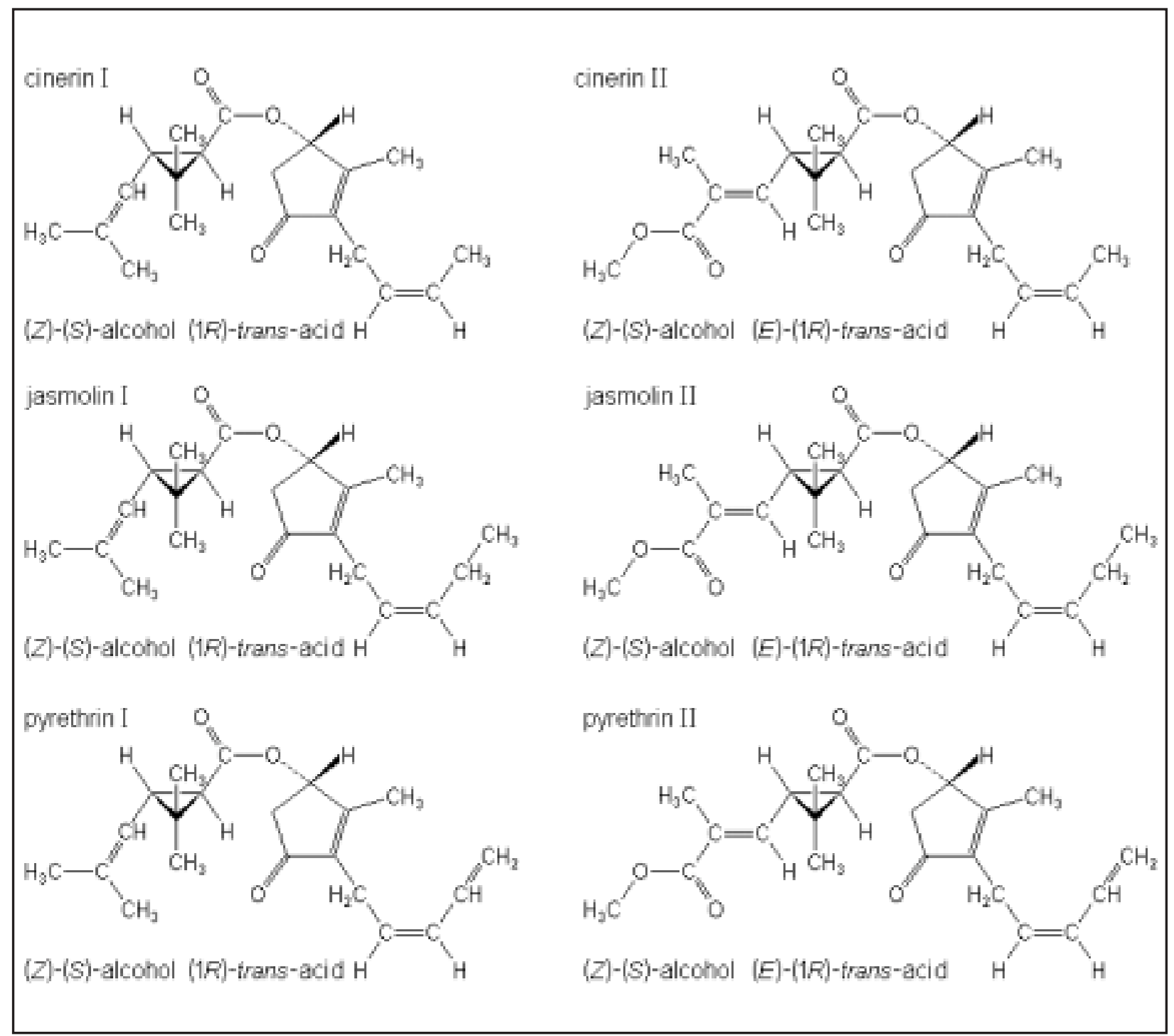

Fig. 1: Structures of the six insecticidal constituents of pyrethrum extract

To-date, many people continue to rely on the use of pyrethrum as a safe insecticide,(Eisner1991).

Besides the pyrethrins non-insecticidal components isolated from pyrethrum flowers which are of interest in this paper need to be cited. Among these are the carotenoids, $\beta$-carotene and $\alpha$-carotene cited to represent only $1 \%$ of the total carotenoid fraction. The flavonoids have also been isolated and characterised in pyrethrum. These are 7-glycosides and 7-glucuronides of apigenin, luteolin, quercetatin and also the 3,6- dimethyl ether and 3,6,4 - trimethyl ether of quercetagetin. In the class of triterpenols and sterols, taraxasterol has been isolated and its structure established (Elliot and Stephenson, 1966). Taraxasterol is undesirable because it is thought to be responsible for the jellying of the refined pyrethrum extract. "Pale" Fukushi (1952) has also, cited the presence of the sterol $\beta$-amyrin. Pyrethrosin thought to be a toxic compound in the Pyrethrum extract was first isolated by Rose and Haller (1937).Quantitative analysis in trace amounts has recently been carried out by Odinga and Ochieng(2000). Most recent of all a sesquiterpene. Pyrethroidin has been reported (Abduazimov et al. 1985). The sesquiterpenoids in 
pyrethrum extract, particularly. Sesamin are reported to be synergistic. However in commercial formulations of pyrethrins, piperonyl butoxide and butulated hydroxy toluene (BHT) are added to augment the insecticidal activity and stabilisation of the pyrethrins respectively.

The pyrethrum extract is visually yellow and this yellowness differs in intensity from one extract to an other. In certain cases much pale appearing extracts have high pyrethrins and vice versa. The flavonoids and carotenoids are naturally yellow pigments and these are thought to be the main cause of the yellow colour of the pyrethrum extract. This paper describes this relationship between the pyrethrins and the yellow pigmentationin of pyrethrum flowers.

\section{EXPERIMENTAL}

\section{General}

All the chemical and instrumental analyses were done in replicates of two or four for the purpose of reproducibility and to enhance accuracy of the final results. Any questionable replicate result(s) obtained from analytical instruments were subjected to acceptability Q-test before an average value was considered (Jeffery et al. I989). All the extractions were made using aromatic freen $n$-hexane (absorbance at $\lambda 225 \mathrm{~nm}$ air ref., $1 \mathrm{~cm}$ cess $=0.003$ ).

De-aromatilization was done as follows: double distillation of crude n-hexane, lefl to cool and gravity run through a $30 \mathrm{crn}$ long by $4 \mathrm{~cm}$ diameter glass column packed with activated silica gd and cdlecting the eluate dropwise, finally absorbance at $\lambda 225 \mathrm{~nm}$ checked using a double beam spectrophotometer. All cold extractions were carried out for one hour aided with mechanical shaking. Hot extractions were achieved using the conventional soxhlet extractor for at least seven hours.

\section{Materials}

Twenty clones and varieties of pyrethrum flowers originating from various localities were picked from Molo nurseries. dried in the shade and ground using a Willey mill to pass $1 \mathrm{~mm}$ screen. Precaution was taken during storage of the research sample to avoid exposure of the grist to extreme heat or direct sunlight which vrould othenvise affect the pyrethrin

\section{Spectrophometry}

A double beam Pye Unicam SP8-150 spectrophotometer was used. Prior to use, the instrument was first calibrated using the world standard pyrethrum extract (WSPE 1992). Absorbances of extracts at 225 were done on $0.5 \%(\mathrm{w} / \mathrm{v})$ aromatic free $n$-hexane cold extracts left to settle overnight and diluted appropriately before reading. Pigment absorbances at the three regions: $265-300 \mathrm{~nm}$. 300 - 400nm and 400 - 470nm were done on $1 \%(\mathrm{w} / \mathrm{v})$ aromatic free $n$-hexane extracts and read without any dilutions. A typical-scan, 700nm - 2501nm of the pyrethrum extract showed absorption peaks at the following wavelengths: 670. 470. 440. 420. 370. 350. 330. 294. 285. 275 and $265 \mathrm{~nm}$.

Calculations of total pyrethrins content were done as follows:

$\%$ Pyrethrins $=$ Absorbance at $\lambda 225 \mathrm{~nm} \times \mathrm{M}+\mathrm{C}$

Where $\mathrm{M}$ and $\mathrm{C}$ are the linear correlation slope and constant respectively between pyrethrin content by AOAC (AOAC. I984) method and mean absorbances at $\lambda 225 \mathrm{~nm}$. Spectrophotometric determination of \% pyrethrins methodology is calibrated against the AOAC mercury reduction assay and it gives good linear regression lines ( Casida. 1973).

The slope and constant in this work were determined using the pye Unicam instrument and the twenty research samples analysed. The values of $\mathrm{M}$ and $\mathrm{C}$ were 154 and 0.19 respectively. The pyrethrum Board of Kenya (Nakuru) slope (M) and constant (C) are 1.44 and 0.29 respectively.

All the spectrophotometric methodology used in this work is based on the fundamental Beer-Lamberts Law:

$\mathrm{A}=\varepsilon \mathrm{cl}$

where

A = Absorbance intensity $\vartheta$

$\varepsilon=$ Molar absorptivity (extinction coefficient)

$1=$ Path length

$\mathrm{A}^{1 \%}{ }_{1 \mathrm{~cm}}=\ddot{\mathrm{A}} \times 100$ $\xi \times \mathrm{P}$

where

$\mathrm{A}^{1 \%} \quad=$ Specific colour absorbance.

$\ddot{\mathrm{A}} \quad=$ Mean absorbance for $1 \%$ extract using $1 \mathrm{~cm}$ cells at a particular region.

$\mathrm{P}=$ Mean Pyrethrins content by AOAC.

$\xi=$ Exact weight $(\mathrm{g})$ of sample used to obtain a $1 \%$ extract.

AOAC

The official methodology of analysis (AOAC. 84) was 
W. A. ODINGA

used. All reagents used were analar grade. n-Hexane used was aromatic free. Standardisation of Sodium hydroxide solutions was done using potassium hydrogen phthalate.

\section{Water Content determination:}

The Dean and Stark apparatus were used with toluene as the organic solvent.

Tables 1, 2 and 3 show the spectrophotornetric, AOAC and HPLC results for the various clone and variety samples collected from Molo. Plots of the specific colour absorbances at region $265-300 \mathrm{~m}\left({ }^{1} \mathrm{~A}\right)$ and $300-$ $400 \mathrm{~nm}\left({ }^{2} \mathrm{~A}\right)$ with pyrethrins content using the INSTAT programme developed at the University of Reading, England on a BBC computer are shown in Fig. 3 and Fig. 4 below. Similarly computer correlations were made with other data and all the correlation coefficients are indicated in table 4 . The moisture content for all the samples ranged from $4 \%-8 \%$

Table 1 Spectrophotometric analysis of various clones

\begin{tabular}{|c|c|c|c|c|c|c|c|c|}
\hline SAMPLE & A $225 \mathrm{~nm}$ & Total Pys (\%) & ${ }^{1} \mathrm{~A}$ & ${ }^{2} \mathrm{~A}$ & ${ }^{3} \mathrm{~A}$ & $\begin{array}{l}{ }^{1} \mathrm{~A}^{1 \%} \\
{ }_{1 C M}\end{array}$ & ${ }^{2} A^{1 \%}{ }_{1 C M}$ & ${ }^{3} \mathrm{~A}^{1 \%} \mathrm{ICM}$ \\
\hline C47 (1) & 0.453 & 0.89 & 0.634 & 0.174 & 0.196 & 72.9 & 20 & 22.5 \\
\hline MARWAN GA $\odot$ & 0.671 & 1.22 & 0.71 & 0.226 & 0.185 & 58.7 & 18.7 & 15.3 \\
\hline NYAMASI BI ๑ & 0.69 & 1.25 & 0.704 & 0.254 & 0.172 & 56.8 & 20.5 & 13.9 \\
\hline $4331(\mathrm{v})$ & 0.78 & 1.39 & 0.719 & 0.213 & 0.164 & 52.1 & 15.4 & 11.9 \\
\hline P4 (v) & 0.793 & 1.41 & 0.753 & 0.216 & 0.151 & 53.8 & 15.4 & 11.9 \\
\hline $\mathrm{MO} / 71 / 423$ & 0.793 & 1.41 & 0.785 & 0.176 & 0.132 & 56.1 & 12.6 & 9.4 \\
\hline $\mathrm{Ks} / 75 / 336$ & 0.818 & 1.45 & 0.73 & 0.174 & 0.181 & 50.7 & 12.1 & 12.6 \\
\hline $\mathrm{Ks} / 75 / 313$ & 0.876 & 1.54 & 0.715 & 0.135 & 0.113 & 466.7 & 8.8 & 7.4 \\
\hline K 235 (v) & 0.911 & 1.59 & 0.741 & 0.194 & 0.24 & 46.9 & 12.3 & 15.2 \\
\hline $\mathrm{Kr} / 74 / 122$ & 0.966 & 1.68 & 0.788 & 0.124 & 0.055 & 47.2 & 7.4 & 3.3 \\
\hline $\mathrm{Mo} / 70 / 112$ & 0.978 & 1.7 & 0.683 & 0.172 & 0.172 & 40.4 & 10.2 & 10.2 \\
\hline $\mathrm{Sb} / 66 / 107$ & 0.978 & 1.7 & 0.762 & 0.176 & 0.179 & 45.1 & 10.4 & 10.6 \\
\hline $\mathrm{Mo} / 70 / 101$ & 1.004 & 1.74 & 0.777 & 0.161 & 0.112 & 44.9 & 9.3 & 6.5 \\
\hline $\mathrm{Mo} / 75 / 4$ & 1.005 & 1.74 & 0.708 & 0.19 & 0.195 & 40.9 & 11 & 11.3 \\
\hline $\mathrm{Mo} / 74 / 443$ & 1.061 & 1.82 & 0.708 & 0.102 & 0.115 & 38.9 & 5.6 & 6.3 \\
\hline L/75/477 & 1.094 & 1.87 & 0.7 & 0.137 & 0.146 & 39.6 & 7.3 & 7.8 \\
\hline Ks/71/16 & 1.113 & 1.9 & 1.669 & 0.15 & 0.154 & 35.2 & 7.9 & 8.1 \\
\hline $\mathrm{Ks} / 70 / 64$ & 1.164 & 1.98 & 0.707 & 0.248 & 0,226 & 35.7 & 12.5 & 11.4 \\
\hline Lt75/487 & 1.17 & 1.99 & 0.704 & 0.215 & 0.197 & 35.4 & 10.8 & 9.9 \\
\hline MoR4/223 & 1.228 & 2.08 & 0.645 & 0.16 & 0.133 & 31 & 7.7 & 6.4 \\
\hline
\end{tabular}

NB: At $99 \%$ confidence limit. \pm 0.54 correlation coefficient is significant for twenty samples (Fisher and Yates 1963

\section{KEY:}

$\mathrm{C}$ - indicates local; v indicates variety samples. The samples bearing neither $\mathrm{c}$ nor $\mathrm{c}$ are hybrid clones

Ks - originating from Kisii; L - originating from Limiru

Mo - originating from Molo; $\mathrm{Kr}$ - originating from Keroka

$\mathrm{Sb}$ - originating from Subukia, Marwanga Nyamasibi and C47 are local clones from kisii.

Slope $(\mathrm{MO}=1.54$ and constant $(\mathrm{c})=0.19$
'I'able 2: AOAC analysis results for the various sample clones and varieties from Molo

\begin{tabular}{|l|r|r|r|r|}
\hline SAMPLE & Pl $\%$ ) & Pll $(\%)$ & Pl + Pll (\%) & P / \\
\hline C47 & 0.34 & 0.53 & 0.87 & 0.65 \\
\hline MARWANGA('c) & 0.65 & 0.56 & 1.21 & 1.16 \\
\hline NYAMASIBI(c) & 0.62 & 0.62 & 1.24 & 1 \\
\hline $\mathbf{4 3 3 1}(\mathbf{V})$ & 0.86 & 0.52 & 1.32 & 1.64 \\
\hline $\mathbf{p 4}(\mathbf{V})$ & 0.77 & 0.63 & 1.4 & 1.22 \\
\hline Mo/71/423 & 0.43 & 0.97 & 1.4 & 0.44 \\
\hline Ks/75/336 & 0.83 & 0.61 & 1.44 & 1.36 \\
\hline Ks/75/313 & 0.54 & 0.99 & 1.53 & 0.55 \\
\hline Ks/35 (v) & 0.79 & 0.79 & 1.58 & 1 \\
\hline Kr/74/122 & 0.7 & 0.96 & 1.67 & 0.73 \\
\hline Mo/70/1124 & 0.87 & 0.82 & 1.69 & 1.06 \\
\hline Sb/66/107 & 0.71 & 0.98 & 1.69 & 0.73 \\
\hline Mo/70/1013 & 0.74 & 0.99 & 1.73 & 0.75 \\
\hline Mo/7Si4 & 0.82 & 0.91 & 1.73 & 0.9 \\
\hline Mo/74/443 & 0.77 & 1.05 & 1.82 & 0.73 \\
\hline L/75/477 & 1.06 & 0.81 & 1.87 & 1.31 \\
\hline Ks/71/6 & 0.9 & 1 & 1.9 & 0.9 \\
\hline Ks/70/64 & 0.79 & 1.19 & 1.98 & 0.67 \\
\hline L/75/487 & 0.81 & 1.18 & 1.99 & 0.69 \\
\hline $\mathbf{M o / 7 4 / 2 2 3}$ & 1.26 & 0.82 & 2.08 & 1.54 \\
\hline
\end{tabular}

Table 3: HPLC analysis for the various clones and varieties from Molo

\begin{tabular}{|c|c|c|c|c|c|c|c|c|c|c|}
\hline SAMPLE & \begin{tabular}{|l}
$\mathbf{J I}$ \\
$(\%)$
\end{tabular} & \begin{tabular}{|l|} 
CI \\
$(\%)$
\end{tabular} & $\begin{array}{l}\text { PI } \\
\%\end{array}$ & $\begin{array}{l}\text { Pl } \\
\%\end{array}$ & $\begin{array}{l}\mathbf{J} 2 \\
\%\end{array}$ & $\begin{array}{l}\text { C2 } \\
\%\end{array}$ & $\begin{array}{l}\mathbf{P 2} \\
\%\end{array}$ & $\begin{array}{l}\text { PII } \\
\%\end{array}$ & $\begin{array}{l}\text { PI+PII } \\
\%\end{array}$ & PI/PI \\
\hline C47 () & 0.02 & 0.02 & 0.3 & 0.34 & 0.02 & 0.06 & 0.3 & 0.38 & 0.72 & 0.89 \\
\hline MARANGA (e) & 0.03 & 0.07 & 0.45 & 0.55 & 0.05 & 0.08 & 0.32 & 0.45 & 1 & 1 \\
\hline NYAMASIBI (c) & 0.03 & 0.07 & 0.45 & 0.55 & 0.05 & 0.08 & 0.321 & 0.45 & 1 & 1.22 \\
\hline P4(V) & 0.06 & 0.04 & 0.59 & 0.69 & 0.06 & 0.05 & 0.37 & 0.48 & 1.17 & 1.44 \\
\hline $43331(v)$ & 0.05 & 0.04 & 0.66 & 0.75 & 0.04 & 0.05 & 0.32 & 0.41 & 1.16 & 1.83 \\
\hline $\mathrm{Mo} / 71 / 423$ & 0.03 & 0.03 & 0.32 & 0.38 & 0.07 & 0.07 & 0.65 & 0.79 & 1.17 & 0.48 \\
\hline $\mathrm{Ks} / 75 / 336$ & 0.07 & 0.05 & 0.66 & 0.78 & 0.05 & 0.05 & $0.34 \mathrm{i}$ & 0.44 & 1.22 & 1.77 \\
\hline $\mathrm{Ks} / 75 / 313$ & 0.03 & 0.04 & 0.36 & 0.43 & 0.06 & 0.08 & 0.701 & 0.84 & 1.27 & 0.51 \\
\hline K235 (v) & 0.05 & 0.06 & 0.64 & 0.75 & 0.05 & 0.07 & 0.47 & 0.59 & 1.34 & 1.27 \\
\hline $\mathrm{Kr} / 74 / 122$ & 0.03 & 0.07 & 0.45 & 0.55 & 0.07 & 0.17 & 0.58 & 0.82 & 1.37 & 0.67 \\
\hline $\mathrm{Mo} / 70 / 114$ & 3 & 0.11 & 0.58 & 0.72 & 0.05 & 0.16 & 0.5 & 0.71 & 1.43 & 1.01 \\
\hline $\mathrm{Sb} / \mathbf{6 6 / 1 0 7}$ & 0.03 & 0.05 & 0.52 & 0.6 & 0.06 & 0.13 & 0.64 & 0.83 & 1.43 & 0.72 \\
\hline Mo/70/103 & 0.06 & 0.07 & 0.56 & 0.69 & 0.08 & 0.13 & 0.57 & 0.78 & 1.47 & 0.88 \\
\hline $\mathrm{Mo} / 75 / 4$ & 0.05 & 0.07 & 0.6 & 0.72 & 0.07 & 0.12 & 0.551 & 0.74 & 1.46 & 0.97 \\
\hline L/75/477 & 0.05 & 0.08 & 0.69 & 0.84 & 0.08 & 0.11 & 0.5 & 0.69 & 1.53 & 1.21 \\
\hline M0/74/443 & 0.07 & 0.04 & 0.63 & 0.71 & 0.07 & 0.09 & 0.68 & 084 & 1.55 & 0.85 \\
\hline $\mathrm{Ks} / 71 / 6$ & 0.04 & 0.08 & 0.7 & 0.82 & 0.06 & 0.13 & 0.58 & 0.77 & 1.59 & 1.06 \\
\hline $\mathrm{Ks} / 70 / 64$ & 0.04 & 0.07 & 0.6 & 0.71 & 0.1 & 0.15 & 0.67 & 0.92 & 1.63 & 0.77 \\
\hline L/75/487 & 0.07 & 0.07 & 0.65 & 0.79 & 0.12 & 0.14 & 0.69 & 0.95 & 1.74 & 0.68 \\
\hline $\mathrm{Mo} / 74 / 223$ & 0.09 & 0.08 & 0.9 & 1.07 & 0.07 & 0.06 & 0.6 & 0.73 & 1.8 & 1.47 \\
\hline
\end{tabular}


The Relationship between Pyrethrins and the Yellow Pigmentation in Pyrethrum Flowers

Table 4: Correlation coefficients of Pyrethrins content and specific colour absorbances

\begin{tabular}{|l|r|r|r|}
\hline & ${ }^{\mathbf{1}} \mathbf{A}^{\mathbf{1}} \mathbf{~} \mathbf{~} \mathbf{m}$ & ${ }^{\mathbf{2}} \mathbf{A}^{\mathbf{1 \%}} \mathbf{1} \mathbf{c m}$ & ${ }^{\mathbf{3}} \mathbf{A}^{\mathbf{1 \%}} \mathbf{1} \mathbf{~} \mathbf{m}$ \\
\hline Total Pys (AOAC) & -0.98 & -0.81 & -0.72 \\
\hline Total Pys (HPLC) & -0.89 & -0.8 & -0.7 \\
\hline PI's (AOAC) & -0.76 & -0.52 & -0.45 \\
\hline PII's (AOAC) & -0.7 & -0.68 & -0.6 \\
\hline PI's (HPLC) & -0.75 & -0.45 & -0.36 \\
\hline JI (HPLC) & -0.51 & -0.35 & -0.31 \\
\hline CI (HPLC) & -0.66 & -0.37 & -0.36 \\
\hline P2 (HPLC) & -0.73 & -0.44 & -0.33 \\
\hline J2 (HPLC) & -0.65 & -0.56 & -0.51 \\
\hline C2 (HPLC) & -0.51 & -0.46 & -0.44 \\
\hline P2 (HPLC) & -0.69 & -0.74 & -0.67 \\
\hline
\end{tabular}

\section{RESULTS AND DISCUSSION}

Tables 1. 2 and 3 show the spectrophotometric, AOAC and HPLC results for the various clone and variety samples collected from Molo. Plots of the specific colour absorbances at region 265 - 300m (1A) and 300 $-400 \mathrm{~nm}$ (2A) with pyrethrins content using the INSTAT programme developed in the University of reading England on a BBC computer are shown in Fig. 2 and Fig. 3 below. Similarly computer correlations were made with other data and all the correlation coefficients are indicated in table 4 . The water content for all the samples ranged from $4 \%-8 \%$, mean $6 \%$

From table 4 above, it is condusive that there exists an inverse correlation between the total pyrethrins and the specific colour absorbances in all the three regions of the electromagnetic spectrum. As the concentration of the pyrethrins increase the specific colour absorbance to decreases. The correlation efficients are acceptable 99\% confidence limit except for the correlation between pyrethrins I and specific colour absorbance, at 300 400nm and $400-470 \mathrm{~nm}$ (Fisher and Yates.1963).

Also from the correlation coefficients there is a better linear correlation between the pyrethrins and pigments absorbing at 265 - 300nm than pigments absorbing at the other two regions. No correlation exists between pyrethrins I and pigments absorbing at $300-400 \mathrm{~nm}$ and 400 - 470nm. However Pyrethrins 11 correlate significantly with these pigments (Figures 2, 3 and 4)

Among the individual ester P2's correlate significantly with the pigments at all the regions. Only Jl's and C2's do not show appreciable inverse correlation with pigments at $265-300 \mathrm{~nm}$.

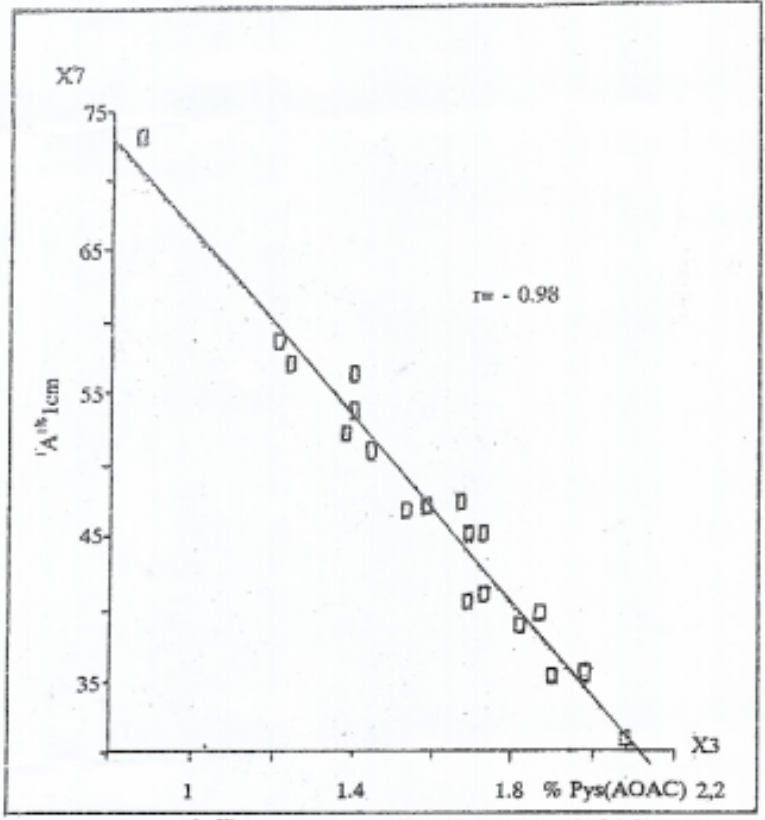

Figure 2: Plot of ${ }^{1} \mathbf{A}^{1 \%} \mathbf{1 c m}$ versus Total Pyrethrins (AOAC)

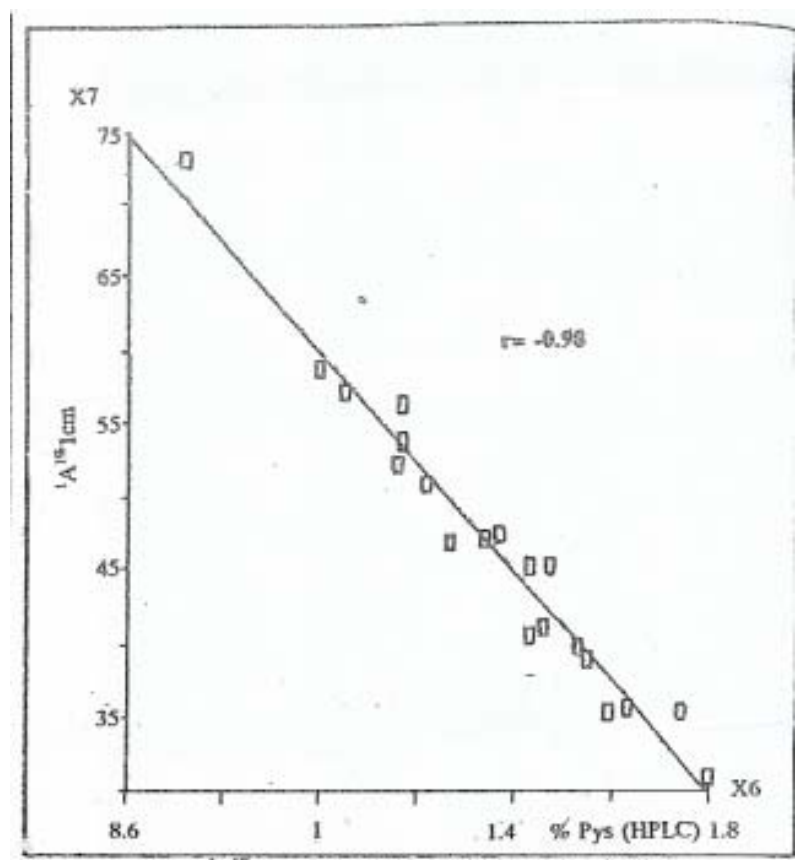

Figure 3: Plot of ${ }^{1} \mathrm{~A}^{1 \%} 1 \mathrm{~cm}$ versus Total Pyrethrins (HPLC) 


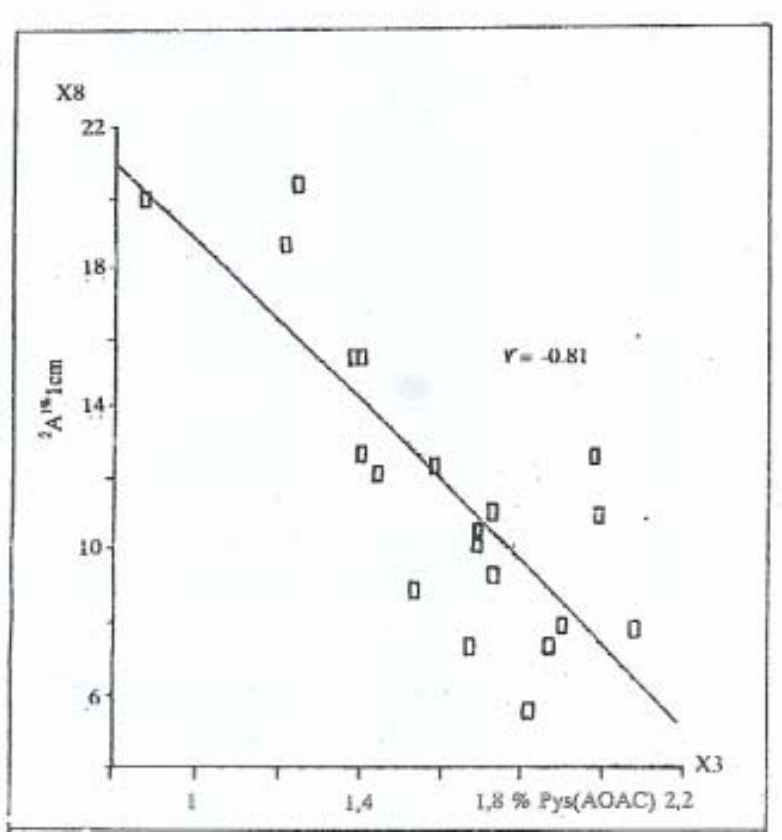

Figure 3: Plot of ${ }^{2} \mathrm{~A}^{1 \%} \mathbf{1} \mathrm{cm}$ versus Total Pyrethrins (AOAC)

These deductions from the above correlation between the pyrethrins and the pigments in pyrethrum extracts prompt an insight into the biosynthetic processes in the pyrethrum plant

NB: At $99 \%$ confidence limit. \pm 0.54 correlation coefficient is significant for twenty samples (Fisher and Yates 1963The biosynthetic pathways for the pyrethrins carotenoids and flavonoids show that all the three classes of compounds are derived from pyruvic acid. Basing on the above correlation, it appears that the rate at which these biosynthetic processes proceed is influenced by certain factors which need further investigation. In flowers with high, Pyrethrins content the pigmentation is diminished. It implies that the very bright flowers have low pyrethrins. Incidentally it has been noted by plant breeders that certain insects still visit and destroy or eat certain flowers in the nurseries and farms. Apart from the fact that these insects may have adapted themselves to this activity these results suggest that the insects visit the very bright flowers which have low pyrethrins concentration. The flowers with high pyrethrins content but low pigmentation are the most desirable in the pyrethrum industry because the processing procedure in the factory involve decolorisation steps. The yellow colour in "pale" is undesirable due to the fact that the pigments stain fabrics and walls when the formulated products are used in households.

In this work the authors were also interested in the ratio of Pyrethrins I to Pyrethrins 11 to find out whether there is any apparent correlation between the ratios and the pigmentation. It is documented that pyrethrins 11 are associated with faster knockdown effect than Pyrethrins I which are thought to exhibit greater killing power than the former (Sawicki and thain, 1962a). These results do not show any apparent linear correlation between the Pl/ PII ratios with the specific colour absorbances. But there is a significant inverse linear correlation between the Pyrethrins 11 and the specific colour absorbances at all the three regions.

Upon the realisation of the factors which favour the pyrethrins pathway of biosynthesis. which may be unfavourable to the carotenogenesis and flavonogenesis. then high pyrethrins and low pigmentation pyrethrum flowers can be achieved.

As a guide, it is already documented that $\beta$ - carotene accumulation in Dunaliella salina is highly influenced by high light intensity, high temperature, high salinity and nitrogen deficiency. These factors have been found to decrease the growth rate of the algae (Erick. 1989). In natural products science. It is possible to control and direct biosynthetic processes. Despite economic and other constraints, future crop improvement programmes should involve a biotechnological approach. The recent American indication of production of abundant and cheap pyrethrins from a biotechnological source in due course could be a possible success in this direction. The role of genetic engineering on pyrethrum plants is already beginning to realise results in India (Singh and Shartna, 1989). In view of this future competitive environment for the pyrethrum industry, the results cited in this paper could form a working basis for future action in this regard.

\section{Conclusion}

These results suggest an inverse linear correlation between the pyrethrins and the yellow pigments. The fact that pyrethrins II show a more significant inverse linear correlation with the yellow pigments at all the three regions is particularly interesting. The 5 correlation between the individual esters and the yellow pigments varies, P2's correlating more significantly draws greater attention. The factors which influence the biosynthetic processes need further 6 research. It is possible to develop the above correlation into a quality control parameter as well as utility of the same in the future 7 crop improvement programmes to achieve flowers of low pigmentation but high pyrethrins content either genetically engineered or agronomically developed. The phytochemistry of the 8 yellow pigments is still in progress. 


\section{Acknowledgement}

The authors are grateful to pyrethrum Board of Kenya (Nakuru) for providing the funds and equipment used to carry out this research project.Appreciation also goes to Dr. A.N Mengech for her assistance in typing and editing of the manuscript.

\section{References}

Casida, J.E; Quisdad, G.B (1995). Pyrethrum Flowers; Production, Chemistry, Toxicology, and Uses. Oxford University Press, New York, ,49.

Casida, J. E.(Ed)., (1973). Pyrethrum, The Natural Insecticide. Academic Press, New York. 3, 43.

Odinga, W.A; Ochieng C.D.(2000) The Relationship between Pyrethrins and the Yellow Pigmentation in Pyrethrum Flowers,Pyrethrum Post18(4)121

Eliot. M., Stephenson, H.. (1966). "Pyrethrol Taraxasterol" - A note Pyrethrum Post. Vol. 8 No. 3 pp 27-28

Maciver, D.R.( 1995) Constituents of pyrethrum extracts. In: Casida, J.E. and Quistad, G.B. (eds). Pyrethrum flowers. Production, chemistry, toxicology, and uses. Oxford University Press, New York. pp. 108 122.

Rose, W.GHaller, H1. (1937). C'onstituents of Pyrethrum Flowers X1, J.Org. C'hem.. 2, 484 -488.
Jeffrey, G. H. Bassett. J., Mendham. J., Denney, R.C., (1989) Vogel's Text book of quantitative Chemical analysis ELBS longman 5th Ed. 137-138, 144 - 146, 842.

Essig, K; Zhao, Z.J.(2001) Preparation and Characterization of a Pyrethrum Extract Standard, LCGC 19, no.17 p.722730.

Kamau, S.M., (1990). Quantitative determination of Pyrethrins by rapid high performance Liquid Chromatographic analysis; Pyrethrum Post 18, (1) $7-10$

Erick, T. Vandamme (Ed.)., (1989). Biotechnology of vitamins, Pigments and growth factors Elsevier applied Science, London and New York. Pp 15 19.

Chandler, S. E., (1951). Botanical aspects of pyrethrum. General considerations: the seat of the-active principles Pyrethrum post 2 (3) ppl.

Fisher, A. R., Yates, F., (1963). Statistical tables for biological, agricultural and medical research 6th ed. LONGMAN p. 63.

Sawicki, R.M., Thain, E. M. (1962a) 'Insecticidal activity of Pyrethrum extract and its knock-down activities of the four constituents. J. Sci.food Agri 13: 292

Singh, S.P; Sharma, J.R., (1989). Genetic Improvement of Pyrethrum for selective divergence, Heterosis and potential hybrid clones. Theor. A. Gen. 78.

Eisner R, (1991) Still Working Out Bugs. The Scientist $5: 12$ 